\title{
The Bacteriology of the Supragingival Plaque of Child Dental Patients in Kuwait
}

\author{
N.O. Salako ${ }^{a}$ V.O. Rotimi ${ }^{b}$ R. Preeta ${ }^{a}$ F. Khodakhast ${ }^{b}$ \\ a Department of Preventive and Developmental Sciences, Pediatric Dentistry Unit, Faculty of Dentistry and \\ bDepartment of Microbiology, Faculty of Medicine, Kuwait University, Kuwait
}

\section{Key Words}

Supragingival plaque $\cdot$ Microbiology $\cdot$ Children $\cdot$ Kuwait

\begin{abstract}
Objective: To investigate the bacterial flora of the gingival plaques of pediatric dental patients in order to establish baseline data for future studies on the complex microbiota of the oral cavity of this group of child dental patients. Subjects and Methods: Forty subjects, aged 312 years, were enrolled and investigated after informed consent was obtained. During the patients' first visit to the dental clinic supragingival plaque samples were collected from the gingival area of buccal and lingual tooth surfaces of all primary and permanent molar teeth using sterile curettes. Serially diluted samples were inoculated onto a set of selective and nonselective media and then incubated at the appropriate atmospheric conditions and temperatures. Representative colonies of isolates were identified by standard methods, including hemolytic characteristics on blood agar and profiling on API $20 \mathrm{~S}$ and API 20A as appropriate. Results: A total of 183 isolates (123 aerobes and 60 anaerobes) were recovered from the 40 patients with a mean count of 3 per sample of aerobes compared to 1.5 per sample for the anaerobes. Streptococcus sanguis was the predominant
\end{abstract}

aerobic species (23.6\%) isolated from 29 (72.5\%) of the 40 patients, followed by Streptococcus mitis, 19.5 and $60 \%$, Streptococcus salivarius, 17.1 and $52.5 \%$ and Streptococcus mutans, 17.1 and $52.5 \%$. The frequency of isolation of anaerobic bacteria was Prevotella spp. 50\% from $30(75 \%)$ of the 40 patients, Fusobacterium spp., 18.3 and $27.5 \%$, Bacteroides spp., Porphyromonas spp. and Peptostreptococcus spp., 6.7 and 10\%, 6.7 and 10\%, and 5 and $7.5 \%$, respectively. Prevotella intermedia was the single most common species. Conclusion: The results show that there were more aerobic/facultative anaerobic bacteria than the obligate anaerobes in the dental plaque of the pediatric dental patients in Kuwait. The high prevalence of the pioneering streptococci as well as black-pigmented Prevotella spp. and Fusobacterium spp. indicates that the dental plaques of the children were in the developing stage, a precursor to the development of periodontal diseases.

Copyright $@ 2004$ S. Karger AG, Basel

\section{Introduction}

The oral cavity provides ecological niches to a large number of diverse microbiota - bacteria, fungi, protozoa and viruses - that form the normal resident flora [1]. Over

\section{KARGER \\ Fax +41613061234 \\ E-Mail karger@karger.ch \\ www.karger.com

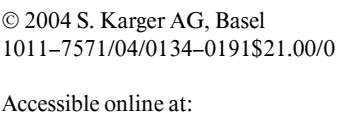

Prof. Nathanael Salako
Faculty of Dentistry, Kuwait University
PO Box 24923
13110 Safat (Kuwait)
Tel./Fax +965 5348947 , E-Mail natsal@hsc.kuniv.edu.kw 
300 different species exist in the human oral cavity [2] The members of this flora exist in a harmonious relationship with the host. However, once this homeostasis is lost, a significant number of these microorganisms can become pathogenic giving rise to opportunistic infections which include mucosal infections, dental caries and periodontal diseases [3-5].

Microbial plaque, which lies in close proximity to gingival tissue, is an important ecological factor instigating gingival inflammation and, in some cases, subsequent loss of the periodontal tissue [1]. Therefore, to evaluate the flora responsible for adverse dental infections, the bacterial population of the dental plaque needs to be examined. Enumeration of microorganisms forming the plaque is important so as to obviate the perpetuation of plaque of dental caries and periodontitis, and also in formulating an informed evidence-based policy on a proper antimicrobial regimen for the treatment of dental infections.

In this study, we present a preliminary report of a prospective study designed to enumerate the distribution of the bacterial population of the supragingival plaques of Kuwaiti child dental patients.

\section{Subjects and Methods}

Forty subjects, aged 3-12 years, who agreed to participate in the study after careful explanation of the objectives to their parents whose consents were obtained, were enrolled and investigated. The supragingival plaque was sampled from the child patients on their first visit to the dental clinic by one of us (N.O.S.). Plaque samples were collected from the gingival area of buccal and lingual tooth surfaces of all primary and permanent molar teeth using sterile curettes. The scrapings were immediately dispersed into $0.3 \mathrm{ml}$ prereduced transport fluid (thioglycollate broth; Oxoid, Basingstoke, UK) and transported by the same clinician without delay to the Anaerobe Laboratory, Department of Microbiology, Faculty of Medicine where all the laboratory investigations were conducted.

In the laboratory, each sample was sonicated and diluted serially (10-fold) in freshly prepared prereduced thioglycollate broth (Oxoid). Then a $0.01-\mathrm{ml}$ aliquot of each dilution was inoculated onto a set of selective and nonselective media. For the enumeration of the oral streptococci, Mitis-Salivarius agar (Difco Laboratories, Detroit, Mich., USA) supplemented with $0.1 \%$ (v/v), and Chapman Tellurite solution with and without bacitracin $0.2 \mathrm{U} / \mathrm{ml}$ (Sigma, St. Louis, Mo., USA) was used [6]. The hemolytic pattern of the streptococcal species was studied using brain heart infusion agar (BHIA; Oxoid) supplemented with 5\% human blood. For the isolation of anaerobes, blood agar (Oxoid) supplemented with gentamicin $75 \mu \mathrm{g} / \mathrm{ml}$ and fastidious anaerobic agar supplemented with hemin $1 \mu \mathrm{g} / \mathrm{ml}$ (Sigma), menadione $1 \mu \mathrm{g} / \mathrm{ml}$ (Sigma), gentamicin $75 \mu \mathrm{g} / \mathrm{ml}$ and $5 \%$ human blood were used; they were freshly prepared daily and prereduced for $2 \mathrm{~h}$ before use.

The plates were incubated at the appropriate atmospheric conditions and temperatures. For aerobic incubations, the plates were held
Table 1. The quantitative and numerical counts of the aerobic and anaerobic flora of the supragingival plaque of Kuwaiti child dental patients

\begin{tabular}{|c|c|c|}
\hline Quantitation & Aerobes & Anaerobes \\
\hline \multicolumn{3}{|l|}{ Total count, cfu/ml } \\
\hline Mean & $5 \times 10^{4}$ & $3.9 \times 10^{5}$ \\
\hline Range & $2 \times 10^{2}-2.8 \times 10^{5}$ & $1 \times 10^{2}-2.4 \times 10^{6}$ \\
\hline \multicolumn{3}{|l|}{ Number of isolates } \\
\hline Mean & 3 & 1.5 \\
\hline Range & $0-6$ & $0-5$ \\
\hline
\end{tabular}

$\mathrm{cfu}=$ Colony-forming unit.

in air at $37^{\circ} \mathrm{C}$ for $24 \mathrm{~h}$ and extended for $48 \mathrm{~h}$ if there was no growth. The inoculated plates meant for anaerobic incubation were placed in anaerobic jars (Oxoid) containing $\mathrm{CO}_{2} 10 \%, \mathrm{H}_{2} 90 \%$, generated by anaerobic gas generating kit (Oxoid), and then placed in the incubator at $37^{\circ} \mathrm{C}$ for $48 \mathrm{~h}$ and 5 days. Quantitative bacterial count of anaerobes and aerobes was made after the appropriate incubation periods. Representative colonies of isolates were identified by standard methods [7].

Streptococci were grouped initially by their hemolytic characteristics on blood agar and also profiling on API 20S (BioMérieux, Hazelwood, Mo., USA). Anaerobes were identified by the lack of growth under aerobic culture, initial susceptibility to metronidazole disk $(5 \mu \mathrm{g})$, colonial and gram strain morphology, and confirmed by specific reactions in API 20A (BioMérieux).

\section{Results}

All the samples from the 40 children were processed for the enumeration of the prominent bacterial flora in the supragingival plaque quantitatively and qualitatively. A total of 183 isolates were recovered from the patients. Table 1 shows the viable bacterial counts and the number of isolates per specimen. In terms of quantitative counts the strict anaerobes were more prevalent than the aerobes by about $1 \log _{10}$. However, the aerobes were numerically more prevalent in the plaques with a mean count of 3 per sample compared to 1.5 per sample for the anaerobes, with ranges of $0-6$ and $0-5$ for aerobes and anaerobes, respectively.

Table 2 shows that a total of 123 isolates were recovered, together with the proportion and frequency of isolation of the different Streptococcus and Lactobacillus species prevalent in the dental plaques. Streptococcus sanguis was the predominant species, representing $23.6 \%$ of all the facultative aerobic flora and it was isolated from 29 
out of 40 patients $(72.5 \%)$. It was followed by Streptococcus mitis, $19.5 \%$ and from 24 out of 40 (60\%), Streptococcus salivarius, $17.1 \%$ and from 21 of $40(52.5 \%)$ and Streptococcus mutans, $17.1 \%$ and from 21 out of 40 (52.5\%). The other streptococci were isolated in relatively low proportions of patients. Lactobacillus species were isolated in only 3 of the 40 patients (7.5\%).

A total of 60 anaerobic bacteria were isolated from the 40 patients. The species, proportion and frequency of isolation of obligate anaerobic bacteria are shown in table 3 . Prevotella spp. were the commonest anaerobe isolated, representing $50 \%$ of the total anaerobes; it was present in the gingival plaque of $30(75 \%)$ out of 40 patients. The next in the ranking order by a far margin was the group of Fusobacterium spp., which represented $18.3 \%$ of the anaerobes and isolated from $27.5 \%$ of the patients. Other notable anaerobes of clinical importance such as Bacteroides spp., Porphyromonas spp. and Peptostreptococcus spp. represented relatively low proportions of the anaerobic flora $(6.7,6.7$ and 5\%, respectively) and were also present in a low number of patients, 10, 10 and $7.5 \%$ respectively. Detailed analysis of the Prevotella species is shown in table 4, which reveals that Prevotella intermedia was the predominant species, representing $36.7 \%$ of the Prevotella spp., followed by the nonpigmented Prevotella oralis 26.6\% and Prevotella melaninogenica $23.3 \%$.

\section{Discussion}

Plaque is generally regarded as a macrohabitat with many microenvironments attributable to the continuous change in the ecological parameters. The progression to and composition of plaque follows a definite pattern of bacterial colonization. Colonization by the so-called pioneer species (S. mitis, Streptococcus oralis, S. sanguis) is followed by a gradual increase in the complexity of the microflora culminating in the establishment of a highly diverse group comprising many spiral, filamentous and obligate anaerobic bacteria [8].

In this study, we established baseline data on the bacterial flora of the supragingival plaque of pediatric dental patients in Kuwait. The data demonstrate a relatively high prevalence of $S$. sanguis and Prevotella spp. at this site. Of course, the relatively high isolation rate of $S$. sanguis, $S$. mitis and $S$. mutans is noteworthy because $S$. sanguis and $S$. mitis comprise a significant part of the pioneer species that contribute to plaque formation usually associated with healthy plaques. The presence of a large number of $S$. mutans is also worth mentioning because this may in
Table 2. Proportion and frequency of isolation of different aerobes in the dental plaque of 40 subjects

\begin{tabular}{lccl}
\hline Bacterial isolates & Isolates & $\begin{array}{c}\text { Proportion } \\
\text { of total, \% }\end{array}$ & $\begin{array}{l}\text { Frequency of } \\
\text { isolation, \% }\end{array}$ \\
\hline Streptococcus sanguis & 29 & 23.6 & 72.5 \\
Streptococcus mitis & 24 & 19.5 & 60 \\
Streptococcus salivarius & 21 & 17.1 & 52.5 \\
Streptococcus mutans & 21 & 17.1 & 52.5 \\
Streptococcus oralis & 8 & 6.5 & 20 \\
Streptococcus constellatus & 4 & 3.3 & 10 \\
Streptococcus acidominimus & 4 & 3.3 & 10 \\
Streptococcus intermedius & 3 & 2.4 & 7.5 \\
Streptococcus bovis & 2 & 1.6 & 5.0 \\
Streptococcus equinus & 2 & 1.6 & 5.0 \\
Streptococcus adjacens & 2 & 1.6 & 5.0 \\
Lactobacillus spp. & 3 & 2.4 & 7.5 \\
\hline Total & 123 & 100 & \\
\hline
\end{tabular}

Table 3. Proportion and frequency of isolation of different anaerobes in dental plaque of 40 subjects

\begin{tabular}{lccl}
\hline Bacterial isolates & Isolates & $\begin{array}{l}\text { Proportion } \\
\text { of total, \% }\end{array}$ & $\begin{array}{l}\text { Frequency of } \\
\text { isolation, \% }\end{array}$ \\
\hline Prevotella spp. & 30 & 50 & 75 \\
Fusobacterium spp. & 11 & 18.3 & 27.5 \\
Bacteroides spp. & 4 & 6.7 & 10 \\
Porphyromonas spp. & 4 & 6.7 & 10 \\
Veillonella spp. & 4 & 6.7 & 10 \\
Peptostreptococcus spp. & 3 & 5.0 & 7.5 \\
Eubacterium spp. $_{\text {Capnocytophaga } \text { spp. }{ }^{1}}$ & 2 & 3.3 & 5.0 \\
Bifidobacterium spp. & 1 & 1.7 & 2.5 \\
& 1 & 1.7 & 2.5 \\
\hline
\end{tabular}

1 Not a strict anaerobe.

Table 4. Frequency of isolation of the different species that make up the Prevotella spp. in the dental plaque of subjects

\begin{tabular}{llc}
\hline Prevotella spp. & $\begin{array}{l}\text { Frequency of isolation from patients } \\
(\mathrm{n}=30)\end{array}$ \\
\cline { 2 - 3 } & $\mathrm{n}$ & $\%$ \\
\hline Prevotella intermedia & 11 & 36.7 \\
Prevotella oralis & 8 & 26.7 \\
Prevotella melaninogenica & 7 & 23.3 \\
Prevotella disiens & 3 & 10 \\
Prevotella bivia & 1 & 3.3 \\
\hline
\end{tabular}


fact signify a shift to a more cariogenic plaque; this is supported by the fact that all the children who participated in this survey had caries with a mean decayed filled teeth (DFT) of $6.5 \pm 2.1$.

In a healthy gingival environment, the predominant microorganisms are gram-positive cocci and rods, and during the maturation of plaque there is gradual shift to a complex community with flora that mainly comprises gram-negative rods including the filaments and the fusiforms [8]. This process plays a predominant role in the progression to periodontitis and gingivitis. Our study demonstrates a high isolation rate of black-pigmented Prevotella spp., followed by the Fusobacterium spp., which, conceivably, suggests the attainment of the developing stage of the plaque in most of our subjects (table 3 ). These findings are in accord with many previous reports that found as many as $61 \%$ of children aged 5-7 years harboring black-pigmented gram-negative anaerobes [911]. P. intermedia was the predominant anaerobic species (table 4), a finding which further supports the fact that the plaque covering the teeth of children in Kuwait are in the developing stage. This is a precursor to progression to periodontitis. This is buttressed by the fact that $P$. intermedia has been known to increase the activity of degradative enzymes under certain conditions, and supports the progression to periodontitis [12].

Another important member of the supragingival flora of the mouth of the pediatric subjects is Fusobacterium spp. These were also isolated from a relatively high number of the subjects and in high proportion after $P$. intermedia (table 4). These organisms have been shown to play an important role in the formation of dental plaque through their ability to extensively coaggregate with many other oral microorganisms [13-17]. Since supragingival plaque can harbor putative periopathogens, as demonstrated in this study, it is conceivable to speculate that it probably plays an important role as a reservoir for such organisms and consequently may lead to the spread to, or reinfection of, subgingival sites [18]. It is therefore reasonable to assume that if the development or maturation of the plaque is undisturbed, or not prevented, it may eventually provide a hospitable milieu for a number of periodontal pathogens.

However, many reports have shown that severe gingivitis and periodontal disease are very rare in healthy, nonmedically compromised children. This has led to the conclusion that the prevalence and severity of gingival diseases may be related to dietary factors, or an age-dependent reactivity to plaque accumulation and/or genetic predisposition and not the mere plaque formation per se.
A few studies in the past demonstrated that with a similar amount of plaque, healthy children tended to have less gingival inflammation than older individuals $[19,20]$. Differences in the immunological response to the periodontic pattern of bacterial flora are a possible explanation for this observation [21-23].

\section{Conclusion}

The results of the present study showed that the profile of the common oral bacteria is essentially in agreement with the findings in similar settings in other geographical parts of the world and that there are more aerobic/facultative anaerobic bacteria than obligate anaerobes in the dental plaque of the pediatric dental patients in Kuwait. The high prevalence of the pioneering streptococci as well as black-pigmented Prevotella spp. and Fusobacterium spp. indicates that the dental plaques of our children are in the developing stage, a precursor to the development of periodontal diseases.

\section{Acknowledgment}

This study was supported by a Kuwait University Research Grant No. DP 01/01, which is gratefully acknowledged. 


\section{References}

1 Marsh P, Martin MV: The resident microflora; in Oral Microbiology, ed 4. Oxford, Wright, 1999, pp 17-33.

2 Moore WE: Microbiology of periodontal diseases. J Periodontal Res 1987;22:335-341.

3 Socransky SS: Relationship of bacteria to the etiology of periodontal disease. J Dent Res 1970;49:203-222.

4 Listgarten MA: Structure of microflora associated with periodontal health and disease in man. A light and electron microscopic study. J Periodontol 1976;47:1-18.

5 Bowen GH, Hardie JM, McKee AS, Marsh PD, Filley ED, Slack GL: The microflora associated with developing carious lesion of the distal surfaces of the upper first premolars in 13-14 year-old children; in Microbial Aspect for Dental Caries. Washington D.C., IRL, 1976, vol 1, pp 223-241.

6 Gold OG, Jordan HV, van Houte J: A selective medium for Streptococcus mutans. Arch Oral Biol 1973;18:1357-1364.

7 Isenberg HD, Baron JE, D'Amato RF, Johnson RC, Murray PR, Rodgers FG, von Graevenitz A: Recommendation for isolation of bacteria from clinical specimen; in Forrest $\mathrm{KV}$, Baron EJ, Murray PR (eds): Manual of Clinical Microbiology, ed 5. Washington, ASM Press, 1991, pp 216-221.

8 Marsh P, Martin MV: Dental plaque; in Oral Microbiology, ed 3. London, Chapman \& Hall, 1992, pp 98-132.
9 De Araujo WC, Macdonald JB: The gingival crevice microbiota of pre-school children. J Periodontol 1964;35:285-289.

10 Frisken KW, Tagg JR, Laws AJ, Orr MB: Suspected periodontopathic microorganisms and their oral habits in young children. Oral Microbiol Immunol 1987;2:60-64.

11 Mackler SB, Crawford JJ: Plaque development and gingivitis in the primary dentition. J Periodontol 1973;44:18-24.

12 Maeda N, Okamoto M, Kondo K, Ishikawa H, Osada R, Tsurumoto A, Fujita H: Incidence of Prevotella intermedia and Prevotella nigrescens in periodontal health and disease. Microbiol Immunol 1998;42:583-589.

13 Kolenbrander PE: Surface recognition among oral bacteria: Multigeneric coaggregations and their mediators. Crit Rev Microbiol 1989;17: 137-159.

14 Kolenbrander PE, Andersen RN, Moore LVH: Coaggregation of Fusobacterium nucleatum, Selenomonas flueggi, Selenomonas infelx, Selenomonas noxia, Selenomonas sputigena with strains from 11 genera of oral bacteria. Infect Immun 1989;57:3194-3203.

15 George KS, Falkler WA Jr: Coaggregation studies of the Eubacterium species. Oral Microbiol Immunol 1992;7:285-290.

16 Falkler WA Jr, Hawley CE: Hemagglutinating activity of Fusobacterium nucleatum. Infect Immun 1977;15:230-238.
17 Eke PI, Rotimi VO, Laughon BE: Coaggregation of black-pigmented Bacteroides species with other oral bacteria. J Med Microbiol 1989; 28:1-4.

18 Ximnez-Fyvie LA, Haffajee AD, Socransky SS: Microbial composition of supra- and sub-gingival plaque in subjects with adult periodontitis. J Clin Periodontol 2000;27:722-732.

19 Longhurst P, Johnson NW, Hopps RM: Differences in lymphocyte and plasma cell densities in inflamed gingiva from adults and young children. J Periodontol 1977;48:705-710.

20 Matsson L, Goldberg P: Gingival inflammatory reaction in children at different ages. J Clin Periodontol 1985;12:98-103.

21 Gillett R, Cruchley A, Johnson NW: The nature of the inflammatory infiltrates in childhood gingivitis. Juvenile periodontitis and adult periodontitis: Immunocytochemical studies using a monoclonal antibody to HLA Dr. J Clin Periodontol 1986;13:281-288.

22 Seymour GJ, Crouch MS, Powell RM, Brooks D, Beckman I, Zola H, Bradley J, Burns GF: The identification of lymphoid cell subpopulations in sections of human lymphoid tissue and gingivitis in children using monoclonal antibodies. J Periodontal Res 1982;17:247-256.

23 Horton JE, Oppenheim JJ, Mergenhagen SE: A role for cell-mediated immunity in the pathogenesis of periodontal disease. J Periodontol 1974:45:351-360. 